\title{
Family Influences on Adolescent Sexual Activity and Alcohol Use
}

\author{
Tsui-Sui Annie Kao* and Winifred Ann Carter
}

\author{
University of Michigan, School of Nursing, 400 North Ingalls Building, Ann Arbor, MI 48109-5482, USA
}

\begin{abstract}
Sexual activity and alcohol use continue to have negative effects on the well-being of today's adolescents. This study used multiple regression analysis to examine relationships among personal factors, family factors, and adolescent sexual activity and alcohol use over three time points. Significant protective factors, which were inversely related to risky behavior, included general adolescent-mother communication, father and family connectedness, and disapproving parental attitudes towards sex. Permissive parenting was associated with self-efficacy for safe sex, early sexual initiation, and increased alcohol use. Health care providers should work to promote positive parent-child relationships and familial protective effects.
\end{abstract}

Keywords: Parent-child relationship, adolescent risky behaviors, sexual onset, alcohol abuse.

\section{INTRODUCTION}

Adolescence is a period of development often marked by experimentation and engagement in new activities. Many adolescents engage in risky behaviors, including early sexual initiation, multiple sex partners, and alcohol use [1-3]. In order to prevent serious physical and psychological health problems during adolescence and later in life, it is critical for family members and health care providers to recognize and eliminate factors related to adolescents' risky health behaviors.

For adolescents, early sexual activity and alcohol use are well documented health problems. In 2007, a report [4] by the U.S. Department of Health and Human Services noted that about $48 \%$ of high school students reported having sexual intercourse, $15 \%$ of whom reported having four or more sexual partners. A longitudinal study of 884 middle school students [5] extrapolated that about $6.2 \%$ of adolescents in the United States have had sex before age 13. Early sexual initiation has been associated with increased health risks and negative health outcomes including lack of condom use, higher rates of sexually transmitted infections (STIs), and teenage pregnancy [2].

Alcohol use during adolescence also is a concern. Approximately $16 \%$ of 12 - to 17 -year-olds reported having their first drink prior to age 13 [6]. In 2009, about $41.8 \%$ of high school students had drunk alcohol [7]. Alcohol use and sexual activity can have compounded effects. A survey analysis [3] of 26,023 students in grades 7-12 from one Midwestern state showed that sexually active male adolescents reported a moderate-to-high level of alcohol use. An event history analysis [8] of 457 adolescents in grades 810 from single-mother and two-parent homes found that those who consumed alcohol were twice as likely to have

*Address correspondence to this author at the University of Michigan, School of Nursing, 400 North Ingalls Building, Ann Arbor, MI 48109-5482, USA; Tel: 734-615-8209; Fax: 734-647-0351;

E-mails: anniekao@umich.edu, anniekao6493@gmail.com had sexual intercourse as those who did not consume alcohol. The correlation between sexual initiation and alcohol use makes it imperative for the health services community to determine potential relationships between these behaviors and an adolescent's personal demographics and family factors.

This study examines the relationship between personal factors, family influences, self-efficacy for safe sex, and adolescent sexual behaviors and alcohol use over three time points. Because there is limited knowledge about family influences on adolescents' development of healthy behaviors, findings from this study will assist community health care providers, mental health care providers, school administrators, counselors, and even parents, by identifying opportunities for intervention which will encourage adolescents to practice healthy behaviors while avoiding risky ones.

\section{BACKGROUND AND SIGNIFICANCE}

Research has suggested several significant predictors of adolescent sexual initiation and alcohol use, including family function, family structure, and adolescents' self-efficacy for engaging in safe sex $[3,5,6,8-10]$. In order to promote more effective communication and preventative care, it is important to determine the relationships between family factors and adolescents' sexual behaviors and alcohol use. The specific aims of this study are to determine a) how personal demographic factors and family structure are associated with adolescent sexual behaviors and alcohol use, b) how family function is associated with adolescent sexual behaviors and alcohol use when controlling for personal factors and family structure, c) how family structure, family function, and self-efficacy, influence adolescent sexual behaviors and alcohol use, and d) how sexual behavior and alcohol outcomes are related in adolescents.

Several studies show a relationship between family structure and adolescent sexual activity. Similar to previous research, for purposes of this study, family structure refers to parental income, marital status, and education attained. 
Recent research has suggested that parent income and socioeconomic status are significant predictors of early adolescent sexual initiation [3]. Specifically, higher socioeconomic status is associated with delay of sexual initiation. Additionally, prior research [8] found a significant association between single-parent families and early sexual intercourse among adolescents. Adolescent girls living in dual-parent families and adolescents boys whose mothers reported higher levels of education were more likely to remain abstinent [5]. Although these findings indicate some associations between family structure and adolescent sexual debut, the relationship between alcohol use, early sexual behaviors, and family structure remains unclear.

We also assessed six variables that address aspects of family function, specifically: adolescents' perceptions of parental attitudes towards sex, degree of permissive parenting, maternal sexual discussion, general adolescentmother communication, and adolescent connectedness with father and family, respectively. Each family function variable is discussed below.

Research [9, 10] has noted significant associations between parents' disapproving attitudes about adolescent sexual intercourse and alcohol use. Disapproving parental attitudes toward early sexual activity and alcohol use were significantly correlated with delayed sexual debut and a decreased likelihood of using alcohol [9, 10]. While disapproving parents communicate their disapproval of risky sexual behavior and alcohol use, a permissive parent acts "in a non-punitive, acceptant, and affirmative manner towards the child's impulses, desires, and actions" [11 p. 889]. Specifically, a permissive parent allows children to regulate their own activities as much as possible, avoids the exercise of control, and does not encourage them to obey externally defined standards.

Research [12-14] has shown that permissive parenting is a significant risk factor for early sexual initiation and alcohol use. Decreased parental involvement and an absence of parental decision making about a child's health were predictors of early sexual initiation [12]. Less permissive parenting, on the other hand, was protective against early adolescent sexual initiation. Daughters with mothers who restricted and monitored their participation in external activities demonstrated a lower risk for sexual activity [13, 14]. In terms of predicting adolescents' alcohol use, however, it is not clear which styles are most protective. Although strict parenting practices are not significantly related to alcohol use, parents' supportive relationship and monitoring practices are related to adolescents' lower likelihood of using alcohol $[9,15,16]$.

Although health care providers are encouraged to urge parents to discuss risks associated with sexual activity with their adolescents, reported results of the effects of maternal sexual discussion on adolescent sexual initiation and alcohol use are inconsistent. Some researchers [5, 17] have suggested that increased maternal sexual discussion is protective against risky health behaviors, whereas others [12, 18] have indicated that maternal sexual discussion is not protective against or predictive of risky behaviors. As reported previously [5], when daughters feel comfortable communicating with their mothers about sex, they are less likely to engage in sex over the following year. However, others $[19,20]$ found no direct link between parent-child sexual discussion and adolescents' risky sexual behaviors. In addition, parent-child communication about alcohol use is not predictive of adolescents' initiation of alcohol uses [18]. These mixed results often are attributed to parents' or adolescents' inconsistent reports about their sexual discussion, delayed timing of engagement in such discussions, or lack of in-depth discussion. While these factors could interfere with successful sexual discussion between parents and adolescents, indirect communication, such as role modeling, monitoring, and adolescents' perceived connectedness with parents and family are important to consider when assessing these diminished effects [16, 17].

An adolescent's perceived connectedness with his or her parents and family is a documented factor in decision making about risky behaviors. Research [3, 10] found a strong protective effect of family connectedness in relation to adolescent sexual debut. Parent and family connectedness has also has been found to be protective against adolescent alcohol use. Specifically, adolescents who reported less frequent use of alcohol also reported higher levels of connectedness with and support from parents and other family members [15, 21, 22]. Additionally, there is an increasing emphasis on understanding and utilizing paternal influences on adolescent development in risky behaviors [16, $22,23]$. In this study, we use longitudinal data from a comprehensive dataset of adolescent behavior to explore evidence of a relationship between adolescents' perceive connectedness with their families and their reported sexual and alcohol behaviors later in adolescence.

\section{Theoretical Framework and Self-Efficacy}

The conceptual model for this study is derived from social cognitive theory [24], which describes human behavior as a triadic, dynamic, and reciprocal process in which behavior, personal factors, and environmental influences interact $[25,26]$. In this study, we operationalize the triadic model with these measurements:

1. Personal factors: age, gender, racial/ethnic background (independent variable)

2. Environmental factors: family structure and family function (independent variable)

3. Behaviors: sexual initiation and alcohol use (dependent variables)

According to social cognitive theory [24, 25, 27, 28] perceived self-efficacy-defined as an individual's belief in his or her ability to produce effects-serves as an important construct in an adolescent's cognitive processing and influences his or her decision making. Social cognitive theory proposes that for adolescents, the interplay of personal competencies, self-management efficacy, and the prevailing influence of influential peers determine whether they forsake risky activities or become chronically enmeshed in them.

Cross sectional studies $[5,13]$ have recognized selfefficacy to engage in safe sex as an important predictor of adolescents' safety in other health behaviors. Self-efficacy is necessary for behavior change because it directly influences effort and performance of any given task [25]. Research [5, 
13] has shown that adolescent males and females who had the self-efficacy to refuse sex also were less likely to engage in sex. Building on these findings, our study examined if adolescent self-efficacy to engage in safe sex is related to current or past family structure or family function, and ways in which their perceived self-efficacy impacts future sexual initiation or alcohol use.

Adolescents' involvement in risky health behaviors is a complex issue that can lead to devastating health consequences and costs to both the individual and the overall health care system. A more explicit understanding of familial influences on adolescents' health risk behaviors will assist health providers who are involved in developing efficacious family-centered intervention programs for use at and individual and community level.

The review of literature suggests several hypotheses which can be tested through statistical analysis of the Add Health dataset: a) family structure is related to adolescents' risky health behaviors; b) family function is predictive of sexual behaviors as well as alcohol use when personal factors are held constant; c) stronger family structure and function are associated with increased self-efficacy for safe sex; and d) alcohol use and sexual behaviors are significantly associated in adolescents. For purposes of this study, family structure includes the variables parental income, marital status, and education; family function includes disapproving parental attitudes about sex, the degree of permissive parenting, parent-adolescent communication, family connectedness, and mother-adolescent communication.

\section{METHODS}

In this study, we conducted a secondary analysis of the nationally representative, longitudinal Adolescent Health (Add Health) dataset [29] across the first three waves of data collection. Prior to conducting the data analysis, we received approval for exemption from IRB review through the University of Michigan Health Science Institutional Review Board (HUM00031244).

\section{Sample}

The study sample used data from the University of North Carolina's Add Health database, which sampled over 100,000 adolescents. The longitudinal data selected for this secondary analysis consisted of data spanning three time points, defined as Waves I, II, and III. This analysis included a combination of questionnaires and in-home interviews with adolescents and parents conducted at Wave I (1994-1995), follow-up interviews with the adolescents at Wave II (1996), and in-home questionnaires and interviews with adolescents and parents at Wave III (2001-2002). For this analysis, inclusion criteria at Wave I consisted of adolescents in grades 7-12 who also participated in Waves II and III. The Add Health researchers considered the mother to be the preferred parent for this study. Our sample included a total of 9,067 adolescents and mothers. In terms of the adolescent population, slightly more females than males were included, $53.8 \%$ to $46.2 \%$. Their mean age at Wave I was 14.50 years $(\mathrm{SD}=1.72$ years). See Table $\mathbf{1}$.

\section{Measures}

Specific variables were extracted from Waves I, II, and III of the Add Health dataset and factor analysis was performed to estimate how much variability was due to common factors prior to establishing reliability. Z-scores then were calculated for each item and summarized to form the independent variables for the regression modeling.

Dependent variables were drawn from Wave III data, which assessed age of sexual initiation (higher value reflects earlier sexual debut), total number of sex partners (1-50), and total alcohol use. The Add Health study measured five aspects of adolescent alcohol use:

1. sexual regret after alcohol use;

2. total days of alcohol use during the past year;

3. the frequency of intoxication;

4. binge drinking within the previous two weeks; and

5. mean alcohol consumption per drinking episode during the past year.

Independent variables were drawn from Waves I and II data. Wave I variables assessed adolescent demographic factors (age, gender, and race), family structure (parent income, marital status, and education level), and family function (adolescents' perceived parental attitudes toward sex, permissive parenting style, mother-adolescent relationships, and adolescent connectedness with their fathers and their families). Personal demographic factors were included in the analysis and subsequently controlled in the multiple regression models. To assess family structure, parent income and education levels were grouped into several categories, with higher values representing higher income and education levels. Parent marital status was recorded into two categories: married and single/divorced/widowed.

Perceived parental attitudes about sex consisted of four responses from adolescents. Higher values represented disapproving parental attitudes about their adolescents engaging in sexual behaviors at Wave IThis measure had a good reliability (Cronbach's $\alpha=.904$ ).

Permissive parenting style consisted of seven items that asked adolescents if their parents allowed them to make their own decisions about curfews, choosing friends, what to wear, watching television, bedtimes, and diet. In other words, permissive parents allowed their adolescents to make decisions freely. While the reliability of the measure was low (Cronbach's $\alpha=.658$ ), we decided to keep the measure in the model because it is frequently suggested that parenting style is an important factor to consider when exploring parental influences $[9,11,30,31]$.

Mother-adolescent relationships were assessed via two domains: sexual discussion and general communication between mothers and adolescents. Mother-adolescent sexual discussion was assessed with five items that asked mothers (or a mother figure) questions about how much they talked with their children about birth control and sex, particularly 
Table 1. Demographic Descriptions of Sample at Wave I (N=9067)

\begin{tabular}{|c|c|c|}
\hline Age $($ Mean $=14.50 ; \mathrm{SD}=1.172)$ & Number & Percentage \\
\hline 12 & 373 & 4.1 \\
\hline 13 & 1731 & 19.1 \\
\hline 14 & 2126 & 23.4 \\
\hline 15 & 2613 & 28.8 \\
\hline \multicolumn{3}{|l|}{ Gender } \\
\hline Male & 4188 & 46.2 \\
\hline Female & 4879 & 53.8 \\
\hline \multicolumn{3}{|l|}{ Racial/Ethnic Background } \\
\hline Asian & 591 & 6.5 \\
\hline Caucasian & 5817 & 64.2 \\
\hline \multicolumn{3}{|l|}{ Parental Education $(($ Mean $=4.65 ; \mathrm{SD}=1.250$} \\
\hline (1) Never went to school & 7 & .1 \\
\hline (2) $8^{\text {th }}$ grade or below & 315 & 3.5 \\
\hline (3) Completed $8^{\text {th }}$ grade without completing high school or without finishing business/vocational school & 767 & 8.5 \\
\hline (4) High school diploma or GED & 2090 & 23.1 \\
\hline (5) Business or trade school after high school, or college without graduating & 2072 & 22.9 \\
\hline (4) $40,001-50,000$ & 789 & 8.7 \\
\hline (5) $50,001-65,000$ & 831 & 9.2 \\
\hline (6) $65,001-1000,000$ & 857 & 9.5 \\
\hline (7) $100,001-999,000$ & 228 & 2.5 \\
\hline \multicolumn{3}{|l|}{ Parent Marital Status } \\
\hline Single, divorced, or widowed & 2319 & 25.6 \\
\hline Married & 8148 & 64.3 \\
\hline Total Sample & $\mathrm{N}=9067$ & $100 \%$ \\
\hline
\end{tabular}

SD: Standard Deviation.

the negative consequences of pregnancy, the dangers of an STI, and the moral/ethical issues of sexual intercourse. These questions consisted of responses on a 1-4 scale, with a higher number representing more frequent discussion between mother and adolescent. Acceptable reliability was noted (Cronbach's $\alpha=.899$ ). General adolescent-mother communication consisted of three items assessing whether adolescents would initiate discussion with their mothers about things happening in school, when something went wrong, and if they were satisfied with the way they communicated with their mothers. These items were reverse coded to associate a higher number with a higher level of communication. An adolescent without a mother or maternal figure was assigned a zero value for this measurement. Reliability was adequate (Cronbach's $\alpha=.834$ ).

We assessed two domains of connectedness to evaluate adolescents' perceived relationship with their fathers and their families. Adolescent-father connectedness consisted of 
four specific questions that asked adolescents about their perceived warmth, satisfaction, closeness, and caring relationships with their fathers. All items regarding father connectedness were reverse-coded to associate a higher score with a higher level of connectedness. The reliability for this measure was good (Cronbach's $\alpha=.850$ ). Family connectedness was assessed via four questions that asked adolescents about their perceptions of parental care, their families' understanding of them, time spent together as a family, and degree of attention paid to each other. A higher score reflected a higher level of connectedness. Reliability for family connectedness measure was acceptable (Cronbach's $\alpha=$.758).

The final independent variable, self-efficacy for safe sex, was drawn from responses at Wave II. Because the dataset did not specifically assess self-efficacy to delay sexual initiation or abstain from alcohol use, self-efficacy to engage in safe sex was used as a proxy for general self-efficacy. This measure of self-efficacy was then regressed to Wave III variables assessing sexual initiation and alcohol-related behaviors. Self-efficacy was assessed via questions about an adolescent's ability to interrupt behaviors leading to sex in order to use birth control, his or her ability to plan for the use of birth control, and his or her ability to resist intercourse in the absence of birth control. These items were re-coded on a 1-5 scale, with a higher number reflecting a higher level of assurance. The reliability for self-efficacy was acceptable (Cronbach's $\alpha=.728$ ).

\section{Data Analysis}

SPSS Statistics 18 was used for data analysis. Multiple regressions were first performed to explore relationships among personal factors, family factors, and reported behaviors. Dependent variables were regressed on independent variables to determine the respective variances. After determining a full model, block regression was performed to determine if the independent variables of family function and self-efficacy remained significant to each dependent variable when the independent variables of family structure and personal factors were held constant. Finally, a correlation analysis was conducted to determine if alcohol use correlated with age of sexual initiation and total number of sex partners.

\section{RESULTS}

The results of our multiple regressions (see Table 2) showed that highly rated personal factors, family structure, and family function contribute to delay of early sexual initiation and alcohol use. Contrary to our hypothesis, selfefficacy for safe sex was significantly associated with early sexual initiation, higher levels of sexual regret after alcohol use, and increased days of alcohol use. None of the family structure variables were significantly related to total number of sex partners. Consistent with our hypothesis, a permissive parenting style was found to be predictive of high selfefficacy, early sexual initiation, and higher level of alcohol use. Mother-adolescent sexual discussion, father-adolescent connected-ness, and general adolescent-mother communication were not significant predictors of any of the alcohol outcome variables. The following are the results organized for each group of independent variables.

\section{Personal Factors}

Age was the most significant personal factor. At Wave I, the adolescent was between grades 7 and 12, approximately 11 - 18 years old. Wave II occurred one year later [29]. The older age of adolescents at Wave I was more likely to report a later sexual initiation $(\beta=-.17, p \leq .001)$ at Wave III and more likely to report a lower average number of drinks consumed in the year prior $(\beta=-.07, p \leq .001)$. Older ages were associated with more days of alcohol use $\beta=.03$, $p \leq .05)$. Male gender was significantly related to a higher degree of self-efficacy to engage in safe sex as reported at Wave $2(\beta=.16, p \leq .001)$. Male gender was found to be a risk factor for a higher number of sex partners, sexual regret after alcohol use, a higher number of days of alcohol use, a higher number of days of intoxication, consuming five or more drinks on one occasion, and higher average number of drinks in the past year.

Adolescents of Asian descent were more likely to report later sexual initiation $(\beta=-.05, p \leq .05)$. African American adolescents experienced the same age of sexual onset and similar number of sexual partners compared with adolescents of other racial groups. In addition, African American adolescents were less likely to report sexual regret after alcohol use and less likely to report using alcohol at Wave III. Adolescents of Hispanic descent $(\beta=-.05, \mathrm{p} \leq .05)$ reported lower than average levels of self-efficacy for safe sex, whereas Caucasian adolescents $(\beta=.06, \mathrm{p} \leq .05)$ were more likely to report a higher degree of self-efficacy for safe sex.

\section{Family Structure}

All family structure variables were significantly protective against early sexual initiation. Parent income was associated with higher self-efficacy for safe sex $(\beta=.07$, $p \leq .001)$, being protective against early sexual initiation $(\beta=$ $-.04, p \leq .0)$, regret of sexual activity due to alcohol use $(\beta$ $=.10, p \leq .001)$, total days of alcohol use $(\beta=.16, p \leq .001)$, total days of intoxication $(\beta=.16, p \leq .001)$, consuming five or more drinks at one time $(\beta=.10, p \leq .001)$, and high average number of drinks in one year $(\beta=.07, p \leq .001)$. Parent education was associated with higher self-efficacy for safe $\operatorname{sex}(\beta=.04, p \leq .05)$, being protective against early sexual initiation $(\beta=-.05, p \leq .05)$, regret of sexual activity due to alcohol use $(\beta=.09, p \leq .001)$, total days of alcohol use $(\beta$ $=.11, p \leq .001)$, total days of intoxication $(\beta=.11, p \leq .001)$, and consuming five or more drinks at one time $(\beta=.05$, $p \leq .05)$. Marital status was found to be associated with being protective against early sexual initiation $(\beta=-.08, p \leq .001)$ but unlike the other factors, adolescents with married parents were associated with fewer days of alcohol use $(\beta=-.04$, $p \leq .05)$.

\section{Family Function}

Every family function variable was significantly associated with adolescent sexual initiation. Disapproving parental attitudes, family- and father-adolescent connectedness, and general adolescent-mother communication were found to be protective against early sexual initiation. Permissive parenting style $(\beta=.04, \mathrm{p} \leq .05)$ and motheradolescent sexual discussion at Wave I $(\beta=.12, \mathrm{p} \leq .001)$ were related to adolescents' early sexual initiation at Wave 3 . 
Table 2. Results of Multiple Regression

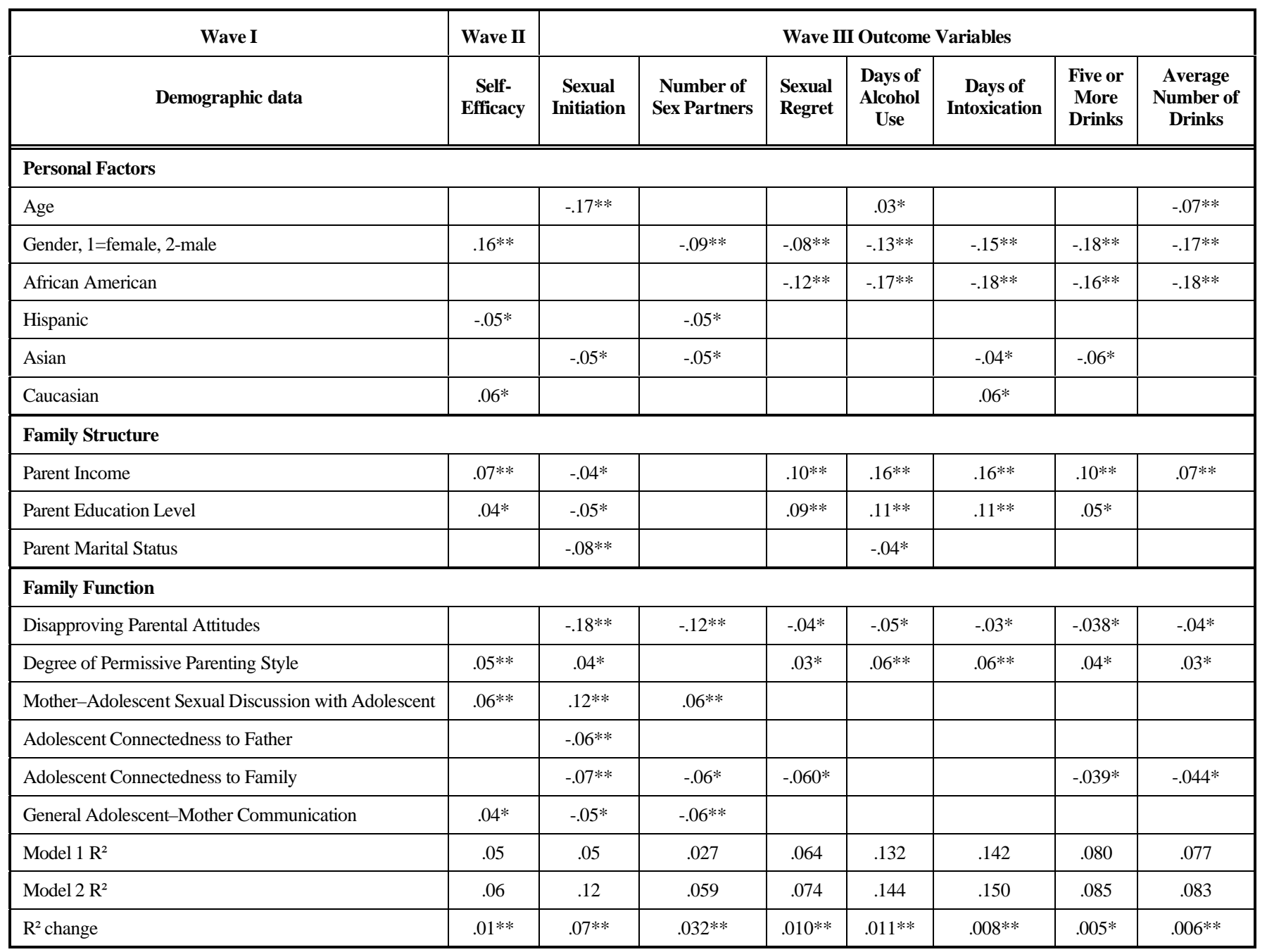

$* \mathrm{p} \leq .05 ; * * \mathrm{p} \leq .001$.

Parental disapproving attitudes and permissive parenting style emerged as the most significant predictors for all sexual behavior and alcohol use outcomes. Disapproving parental attitudes were protective against early sexual initiation $(\beta=$ $.18, \mathrm{p} \leq .001)$, total number of sex partners $(\beta=-.12, p>.001)$, sexual regret after alcohol use $(\beta=-.04, p \leq .05)$, days of alcohol use $(\beta=-05, p \leq .05)$, days of intoxication $(\beta=-.03$, $p \leq .05)$, five or more drinks on one occasion $(\beta=-.04$, $p \leq .05)$, and average number of drinks in the past year $(\beta=-$ $.04, p \leq .05)$. Permissive parenting style was associated with higher self-efficacy specific to engage in safe sex $(\beta=.05$, $p \leq .001)$, but was a risk factor for early sexual initiation $(\beta$ $=.04, p \leq .05)$, sexual regret after alcohol use $(\beta=.03, p \leq .05)$, days of alcohol use $(\beta=.06, p \leq .001)$, days of intoxication $(\beta$ $=.06, p \leq .001)$, five or more drinks on one occasion $(\beta=.04$, $p \leq .05)$, and average number of drinks in the year prior $(\beta$ $=.03, p \leq .05)$. Disapproving parental attitudes, motheradolescent sexual discussion, and general adolescent-mother communication at Wave I were positively associated with adolescent self-efficacy to engage in safe sex at Wave II.

As an independent variable, self-efficacy to engage in safe sex was found to be significantly associated with early sexual initiation $(\beta=.05, p \leq .05)$. Adolescents who reported a high level of self-efficacy for engaging in safe sex at Wave II also reported an earlier age of sexual initiation at Wave III. We also found self-efficacy for safe sex to be associated with higher levels of sexual regret after alcohol use $(\beta=.03$, $p \leq .05)$ and increased days of alcohol use $(\beta=.05, p \leq .05)$.

\section{Correlation Among Dependent Variables}

All alcohol outcome variables were positively correlated with total number of sex partners. That is, adolescents who reported any form of excessive drinking (defined by duration, amount, intoxication, or on average) were more likely to have multiple sex partners $(r=.124-.160, p \leq .05)$. Sexual regret after alcohol use was closely related to total number of sex partners at Wave III $(r=.221, p \leq .05)$. Conversely, early sexual initiation was only related to sexual regret after alcohol use $(r=.037, p \leq .05)$ and excessive drinking, five or more drinks either within 2 weeks $(r=.041$, $p \leq .05)$ or 12 months $(r=.041, p \leq .05)$. Number of days drinking and number of days of intoxication were not found to be statistically significant with regard to early sexual initiation.

\section{Variances Explained}

After controlling for personal and family structure factors, our models explained $3-14 \%$ of the variance over all 
outcome variables. After entry of family function, the model explained an additional .5-7\% ( $R^{2}$ change =.005-.72). Although the $\mathrm{R}^{2}$ change values were small, they were all significant ( $p \leq .05$, see Table 2 ).

\section{DISCUSSION}

While personal factors and family structure relate to adolescent risky health behaviors, this study shows several modifiable family function variables also contribute to adolescent behavior. These modifiable factors include disapproving parental attitudes, structured parenting style, father and family connectedness, and general adolescentmother communication. More importantly, when personal factors and family structure are held constant, the effect of family function is significant over time. An understanding of the modifiable family function variables provides health care workers meaningful points of discussion with adolescents and their families. Providers may be able to offer interventions that maximize a family's protective effects thereby decreasing adolescents' risky behaviors. For example, working with families to increase parental disapproval about adolescent sexual activity may be an effective way to decrease an adolescent's likelihood of engaging in risky behaviors. Although parents' marital status and income might contribute to adolescents' early sexual initiation, this research echoes previous reports [3] which suggest that more frequent parental supervision may be beneficial in delaying adolescent sexual initiation.

Our results show that while higher parent income and education levels are protective against early sexual initiation, they are also risk factors for adolescent alcohol use. This might be attributed to differences in perceived social norms about drinking: more affluent parents may inadvertently model drinking behavior as an acceptable social activity. Such adolescents may also have more access and more opportunities to consume alcohol. Since adolescents' alcohol use is highly correlated with adolescents' multiple sexual partners and is a co-factor for HIV, it is important to develop strategies to minimize such risk [32-34].

A higher degree of permissive parenting style was found to be associated with early sexual initiation and alcohol use at Wave III. If we understand permissive parenting to be indicative of a decrease in structured parenting practices (i.e., parental monitoring), this finding correlates with the impact of protective parental monitoring with regards to delaying adolescent sexual debut $[13,16]$. Since we did not find adolescent self-efficacy for engaging in safe sex to be protective against risky sexual behaviors, we suspect that adolescents' confidence in their ability to stop sexual activity when they do not have condoms or are highly aroused might be overestimated, particularly for those who were not sexually active at an earlier time point (Wave II).

It is possible that this aspect of self-efficacy is not sufficient to explain adolescents' risky behaviors over time. Self-efficacy is a domain-specific competency [28]. Though self-efficacy beliefs can increase and sustain an individual's motivation, efficacy beliefs alone will not produce desired behavioral outcomes if other sub-skills needed for such action are lacking. Thus, it is important for an adolescent to develop other elements of efficacy, such as self-regulation $[25,28]$, which is an individual's ability to take control of his/her behavior in order to obtain a desired outcome,. Ultimately, managing these pressures and resisting risky activity requires the adolescent to use a range of selfregulation and self-efficacy techniques [28].

Adolescent family connectedness was also found to be highly protective against risky behaviors. Feeling part of a close family may help fulfill an adolescent's need to beloved or connected. Early sexual relationships may substitute for family closeness when the latter does not exist [3]. Families operate as multiple social systems, with multiple interlocking relationships [35]. As such, it is important to assess how the family functions as a whole. It has been suggested [25, 27, 28 ] that parental efficacy and family efficacy may play an important role in adolescents' development of various aspects of self-efficacy. For example, our results showed that while adolescents' perceptions of general communication with their mothers was protective against early sexual initiation and number of sex partners, mother-adolescent sexual discussion was not similarly protective. It is possible that a mother's openness to allowing her adolescent to communicate feelings through general communication may be more effective than lecturing a teenager on the negative consequences of sex. Consequently, a closer motheradolescent relationship may facilitate adolescents' mindfulness to mothers' expectations and enhance acceptance of their parents' values and beliefs.

Questions remain concerning the relationship between alcohol use and sexual behaviors. Although a causal relationship could not be established by this study, the associations among family function, drinking patterns, and sexual behaviors cannot be ignored. Congruent with the literature [36], we not only found that disapproving parental attitudes about sex were protective against early sexual initiation and multiple sex partners, but we also found them to have a protective effect on drinking behavior over time. This verifies the importance of parental influence, particularly perceived parental attitudes, on the development of an adolescent's health behaviors, including decisions about when to have sex and consume alcohol. It is critical for health care providers to encourage parents to connect with their children and help parents learn effective ways to express their attitudes, values, expectancies, and beliefs about health behaviors without fear.

Across all outcome measures, the $\mathrm{R}^{2}$ change was found to be low. To explore this further, other factors may need to be added to the analysis. Furthermore, the variables in the Add Health dataset were not specifically designed for our study. Each variable should be explored in-depth to determine its specific factors and their contribution to risky behaviors. Additionally, parenting style should be further explored because of the low reliability. Different dimensions of parenting style should be examined, such as degree of parent demandingness (i.e., a parent's willingness to set behavior expectations for his or her child) [11].

Although the Add Health study surveyed adolescents and families between 1994 and 2002 and findings may not be directly applicable to contemporary adolescents, the longitudinal data is especially useful for understanding parental influences on adolescents' behavior concerning their health choices. The time span of the original dataset, coupled with its size and scope, provide insight into the long term 
effect of parental and family influences upon a range of adolescent behaviors. More research is needed to help explain how self-efficacy specific for safe sex predicted early sexual initiation, sexual regret after alcohol use, and more frequent alcohol use. To help explain this finding, future studies should address adolescent health by designing more specific tools which can specifically measure selfefficacy.

\section{CONCLUSIONS}

Risky adolescent behaviors are a serious health issue. Our results support the protective effects of modifiable family function variables, specifically disapproving parental attitudes, connectedness to family, and adolescents' communication with their mothers. Overall, these results indicate that health professionals who work with adolescents in the community should be alert to adolescents' potentially overestimated confidence, which may manifest itself in the areas of sexuality and alcohol use.

Our findings suggest that while mother-child discussion about sex might be important, it is statistically significant that adolescents who feel connected and have a stronger relationship with their parents will be more likely to have later sexual onset and fewer sex partners. Thus, to prevent adolescents from risky behaviors, it is imperative for health care professionals to encourage strengthening of communication and boundaries between adolescents and their parents and families. Specifically, health care providers and others involved in the health of adolescents can work to increase modifiable family function factors, including disapproving parental attitudes, increased parental monitoring, father and family connectedness, and general adolescent-mother communication. It has been shown that parental behavior can be changed and has a positive effect on adolescent health outcomes. According Hawkins, Catalano, and Miller [37], parenting skills training and parental involvement have been shown to produce protective effects on adolescent health behavior. Health care providers should encourage parents to provide sufficient guidance and monitoring to steer adolescents away from risky situations. As adolescents try to negotiate personal and social pressures, parents need to provide opportunities and support for their adolescents to learn and develop self-regulation efficacy. Health care professionals can play an integral role in this dynamic learning process by providing parents continued training and support.

\section{CONFLICT OF INTEREST}

The authors confirm that this article content has no conflict of interest.

\section{ACKNOWLEDGEMENTS}

This research uses data from the National Longitudinal Study of Adolescent Health, a project directed by Kathleen Mullan Harris and designed by J. Richard Udry, Peter S. Bearman, and Kathleen Mullan Harris at the University of North Carolina at Chapel Hill, and funded by grant P01HD31921 from the Eunice Kennedy Shriver National Institute of Child Health and Human Development with additional funding from 23 other federal agencies and foundations. Special acknowledgment is given to Ronald R. Rindfuss and Barbara Entwisle for assistance in the original study design. Information on how to obtain the Add Health data files is available on the Add Health website (http://www.cpc.unc.edu/addhealth). No direct support was received from grant P01-HD31921 for this analysis.

\section{REFERENCES}

[1] Centers for disease control and prevention. National youth risk behavior survey overview. Atlanta, GA: U.S. Department of Health and Human Services, Division of Adolescent and School Health 2009.

[2] Eaton DK, Kann L, Kinchen S, et al. Youth risk behavior surveillance - United States, 2009. USA: Department of Health and Human Services: Centers for Disease Control and Prevention June 4, 2010

[3] Lammers C, Ireland M, Resnick M, Blum R. Influences on adolescents' decision to postpone onset of sexual intercourse: a survival analysis of virginity among youths aged 13 to 18 years. J Adolesc Health 2000; 26(1): 42-8.

[4] Eaton DK, Kann L, Kinchen S, et al. Youth risk behavior surveillance-United States, 2007. USA: Department of Health and Human Services: Centers for Disease Control and Prevention 2008.

[5] Laflin MT, Wang J, Barry M. A longitudinal study of adolescent transition from virgin to nonvirgin status. J Adolesc Health 2008; 42(3): 228-36.

[6] Center for Disease Control Prevention. National Youth Risk Behavior Survey Overview. Atlanta, GA: US Department of Health and Human Services, Division of Adolescent and School Health 2009.

[7] Centers for Disease Control and Prevention. Youth Risk Behavior Surveillance - United States, 2009. USA: Department of Health and Human Services Centers for Disease Control and Prevention. June 4,2010

[8] Whitbeck LB, Yoder KA, Hoyt DR. Early adolescent sexual activity: a developmental study. J Marriage Fam 1999; 61(4): 93446.

[9] O'Donnell L, Stueve A, Duran R, et al. Parenting practices, parents' underestimation of daughters' risks, and alcohol and sexual behaviors of urban girls. J Adolesc Health 2008; 42(5): 496502.

[10] Resnick MD, Bearman PS, Blum RW, et al. Protecting adolescents from harm. Findings from the National Longitudinal Study on Adolescent Health. JAMA 1997; 278(10): 823-32.

[11] Baumrind D. Effects of authoritative parental control on child behavior. Child Dev1966; 37: 887-907.

[12] Alexander CS, Astone NM, Bandeen-Roche K, Ensminger ME, Mekos D, Roche KM. Parenting influences on early sex initiation among adolescents: how neighborhood matters. J Fam Issues 2005; 26(1): 32-54

[13] Dancy BL. African-American adolescent females' predictors of having sex. J Natl Black Nurses Assoc 2006; 17(2): 30-8.

[14] Dancy BL, Crittenden KS, Ning H. African-American adolescent girls' initiation of sexual activity: survival analysis. Womens Health Issues (WHI) 2010; 20(2): 146-55.

[15] DeHaan L, Boljevac T. Alcohol use among rural middle school students: adolescents, parents, teachers, and community leaders' perceptions. J Sch Health 2009; 79(2): 58-66.

[16] Lohman BJ, Billings A. Protective and risk factors associated with adolescent boys' early sexual debut and risky sexual behaviors. J Youth Adolesc 2008; 37(6):723.

[17] Riesch SK, Anderson LS, Krueger HA. Parent-child communication processes: preventing children's health-risk behavior. J Spec Pediatr Nurs 2006; 11(1): 41-56.

[18] Ennett ST, Bauman KE, Foshee VA. Parent-child communication about adolescent tobacco and alcohol use: what do parents say and does it affect youth behavior? J Marriage Fam 2001;63(1):48-62.

[19] Rodgers KB. Parenting processes related to sexual risk-taking behaviors of adolescent males and females. J Marriage Fam 1999; 61(1): 99-109.

[20] Kao TA, Loveland-Cherry C, Guthrie B. Maternal influences on Asian American Pacific Islander adolescents' perceived maternal sexual expectations and their sexual initiation. J Fam Issues 2010; 31(3):381-406.

[21] Resnick MD, Bearman PS, Blum RW, et al. Protecting adolescents from harm: findings from the national longitudinal study on adolescent health. JAMA 1997; 278(10): 823-32. 
[22] Rienks SL, Wadsworth ME, Markman HJ, Einhorn L, Moran Etter E. Father involvement in urban low income fathers: baseline associations and changes resulting from preventive intervention. Fam Relations 2011; 60(2): 191-204.

[23] Amoran OE. Parental influence on reproductive health behaviour of youths in Ibadan, Nigeria. Afr J Med Med Sci 2008; 37(1): 21-7.

[24] Bandura A. Self-efficacy: toward a unifying theory of behavioral change. Psychological Rev 1977;84(2):191-215.

[25] McAlister, AL, Perry CL, Parcel GS. How individuals, environments, and health behavior interact: social cognitive theory. In: Glanz K, Rimer BK, Lewis FM, eds. Health behavior and health education: theory, research and practice. 4th ed. San Francisco, CA: Jossey-Bass 2008.

[26] Bandura A. Social cognitive theory in cultural context. Appl Psychol-Int Rev 2002;51(2):269-90.

[27] Bandura, A, Caprara, GV, Barbaranelli, C, Regalia, C, Scabini, E. Impact of family efficacy beliefs on quality of family functioning and satisfaction with family life. Appl Psychol-Int Rev 2011; 60: 421-48.

[28] Bandura A. Adolescent development from an agentic perspective. Greenwich, Connecticut: IAP information age publishing, 2006.

[29] National longitudinal study of adolescent health (Add Health): Research Design, 2009. [cited: $29^{\text {th }}$ Nov 2012]. Available from: http://ww.cpc.unc.edu/projects/addhealth/design.

[30] Bush, KR, Supple, AJ, Lash, SB. Mexican adolescents' perceptions of parental behaviors and authority as predictors of their self- esteem and sense of familism. Marriage Fam Rev 2004; 36(1/2), 35-65.

[31] Chen Z, Dornbusch SM, Liu RX. Direct and indirect pathways between parental constructive behavior and adolescent affiliation with achievement-oriented peers. Child Fam Stud 2007; 16(6): 837-58.

[32] Balodis IM, Potenza MN, Olmstead MC. Binge drinking in undergraduates: relationships with sex, drinking behaviors, impulsivity, and the perceived effects of alcohol. Behav Pharmacol 2009; 20(5-6): 518-26.

[33] Quinn PD, Fromme K. Self-regulation as a protective factor against risky drinking and sexual behavior. Psychol Addict Behav 2010; 24(3): 376-85.

[34] Testa M, Hoffman JH, Livingston JA. Alcohol and sexual risk behaviors as mediators of the sexual victimization-revictimization relationship. J Consult Clin Psychol 2010; 78(2): 249-59.

[35] Cox MJ, Paley B. Families as systems. Annu Rev Psychol 1997; 48: 243-266.

[36] Bersamin M, Todd M, Fisher DA, Hill DL, Grube JW, Walker S. Parenting practices and adolescent sexual behavior: a longitudinal study. J Marriage Fam 2008; 70(1): 97-112.

[37] Hawkins JD, Catalano RF, Miller JY. Risk and protective factors for alcohol and other drug problems in adolescence and early adulthood: implications for substance abuse prevention. Psychol B 1992; 112: 64-105. 